\title{
This is America: relatos e reflexão em torno de uma prática educativa
}

Júlio César Virgínio da Costa* Thaís de Ribeiro Pacheco**

\begin{abstract}
Resumo:
Este artigo tem como objetivo partilhar e promover reflexões em torno de uma prática educativa efetivada dentro da estrutura curricular do Centro Pedagógico da UFMG denominada Grupo de Trabalho Diferenciado (GTD). O foco do GTD está centrado em práticas educativas com os discentes por meio da promoção de deslocamentos e de ações por intermédio de ferramentas lúdicas e dinâmicas, sendo a música a principal ferramenta usada no This is America, em busca de apresentar outras experiências para os discentes envolvidos, tanto aos alunos do CP/UFMG quanto aos graduandos monitores. Além disso, buscou-se o desenvolvimento integral dos envolvidos, observando as múltiplas dimensões do ser humano no trabalho pedagógico. Para efetivação de nossos objetivos, cada aula teve como foco um tema específico e, por meio de diferentes mecanismos, os educandos foram sensibilizados perante cada temática e instigados a refletir sobre consequências palpáveis de cada assunto abordado em sala de aula no seu próprio cotidiano.
\end{abstract}

\section{Palavras-chave:}

Prática educativa. Produção cultural. Mídias sociais. Atualidades. Ensino.

\begin{abstract}
:
This article aims to share and promote reflections on an educational practice undertook within the curriculum structure of the Pedagogical Center of UFMG called Differential Working Group (GTD). The focus of the GTD is centered on educational practices with students through the promotion of displacement and actions through ludic and dynamic tools, being the music the main tool used in This is America, in order to present other experiences for the students involved, both to students of the CP/UFMG and graduate monitors. In addition, we searched to provide the integral development of those involved, observing the multiple dimensions of the human being in pedagogical work. To achieve our goals, each class was focused on a specific theme and, through different mechanisms, students were sensitized to each theme and encouraged to reflect on the tangible consequences of each subject addressed in class in their own daily lives.
\end{abstract}

\section{Keywords:}

Educational practice. Cultural production. Social media. Current events. Teaching.

\footnotetext{
* Doutor em Educação pela UFMG, subcoordenador do Núcleo de História e membro do Laboratório de Estudos e Pesquisas em Ensino de História (Labepeh), professor de História do Centro Pedagógico da Escola de Aplicação da UFMG.

E-mail: juliocesarhistoria@gmail.com. ORCID iD: http://orcid.org/0000-0002-1184-591X.

** Graduanda em História pela Universidade Federal de Minas Gerais, foi professora da disciplina GTD: THIS IS AMERICA no

Centro Pedagógico da Escola de Aplicação da UFMG em 2019 pelo Programa de Imersão Docente.

E-mail: thaisripacheco@gmail.com. ORCID iD: http://orcid.org/0000-0003-2344-2007.
} 


\section{Introdução}

O GTD, Grupo de Trabalho Diferenciado, compõe a estrutura curricular do Centro Pedagógico da UFMG no qual professores e monitores, dos projetos de extensão Programa de Imersão Docente (PID) e Programa de Monitoria da Graduação (PMG), oferecem aulas semanalmente em que os educandos de cada ciclo decidem qual assistir previamente. O GTD This is America foi desenvolvido por Júlio César Costa, professor de História, e por Thaís Pacheco, bolsista do PID. O foco dessa matéria está centrado na promoção de práticas educativas que promovam deslocamentos aos educandos e ações que possam ser mais lúdicas, mais dinâmicas e que apresentem outras experiências para os discentes envolvidos.

O nome "This is America” refere-se a uma música de mesmo nome, escrita e interpretada pelo artista Childish Gambino, que aborda tanto em sua letra, quanto em seu clipe, as raízes e consequências do racismo na sociedade, dentre outras questões atuais. O objetivo desta escolha foi atrair o corpo discente por meio de uma linguagem próxima da realidade dos jovens na contemporaneidade. Cada aula teve um tema específico e buscou-se a sensibilização e a reflexão sobre consequências palpáveis de cada temática no cotidiano dos próprios educandos, por meio de músicas e, também, de filmes, dinâmicas, jogos, dentre outros. Além disso, aos discentes foi feito o convite de produzir um podcast que trouxesse uma reflexão acerca de alguma das problemáticas estudadas ao longo do semestre e, também, foram realizadas atividades sobre as temáticas abordadas e um trabalho final, um diário escrito por cada educando sobre cada aula assistida.

É preciso ressaltar que o This is America foi ofertado na grade curricular do Centro Pedagógico UFMG no primeiro e no segundo semestre de 2019 para todo o terceiro ciclo (sétimo, oitavo e nono anos), entretanto esse artigo focará apenas nas turmas do primeiro semestre, dado que o X SICEA ${ }^{1}$ ocor- $^{-}$ rera durante o segundo semestre e a turma desse período ainda não havia concluído suas atividades. O grupo focal desse artigo é composto por três turmas compostas por alunos dos três anos do terceiro ciclo, contando com uma média de 15 estudantes cada.

\section{Metodologia}

Ao longo do semestre, para abordar as temáticas escolhidas, músicas foram selecionadas em conjunto com outros suportes, como filmes, dinâmicas de grupo, podcasts e documentários para abordá-las. Vale salientar que os temas mais abordados em sala iam de encontro com os temas em alta nas discussões travadas nos meios de socialização infanto-juvenis.

Os temas foram previamente levantados por meio de pesquisas feitas em redes sociais (Instagram, Twitter, Tumblr, etc.) e nos meios de produção e disseminação cultural, como conteúdos produzidos por emissoras televisivas, Netflix, YouTube, dentre outros, direcionados aos adolescentes entre 11 e 15 anos. Logo, foi delineado um percurso prévio, mas não rígido, sobre quais temáticas seriam levadas para a sala de aula e trabalhadas com os educandos.

Vale ressaltar que todas as aulas do This is America foram ministradas pela Thaís Pacheco com orientação prévia do professor Júlio César Costa. Isso ocorre por conta da estruturação do projeto no qual a bolsista está inserida, o PID, uma vez que uma das principais atividades desse é a oferta de ao menos um GTD por semestre pelos graduandos bolsistas, podendo ministrá-los sozinhos ou em conjunto com mais um bolsista ou professor. O This is America contou, também, com a participação de outros bolsistas ocasionalmente, como Marcos Vinícius Liberato, bolsista do PID e graduando em Geografia, e Luiz Gustavo Magalhães Alves, bolsista do PMG e graduando em Ciências Biológicas.

Sendo a música o principal mecanismo usado para abordar os temas de cada aula, foi preciso entender as possibilidades de seu uso em sala. Para isso, deve-se primeiro observar que

\footnotetext{
1. X Simpósio dos Colégios de Aplicação das Universidades Federais do Brasil. Encontro ocorrido entre 12 e 14 de novembro de 2019 onde esse trabalho foi apresentado, em sua versão oral, nos diálogos abertos.
} 
[há], basicamente, dois tipos de material didático: os suportes informativos e os documentos. Os suportes informativos têm enfoque pedagógico explícito e correspondem a todo discurso, veiculado em qualquer suporte, "produzido com a intenção de comunicar elementos do saber das disciplinas escolares". (BITTENCOURT, 2012, p. 296).

Já os documentos dizem respeito aos discursos que não são originalmente produzidos na perspectiva dos saberes escolares, mas que no ato educativo são apropriados com finalidade didática. [...] O documento é portador de uma narrativa histórica, no sentido de que informa sobre determinado(s) contexto(s), por meio da construção e da veiculação de representações sociais. Pode-se pensá-lo como uma entidade composta por diferentes dimensões - elementos que constituem a sua totalidade e que, embora possam se observados em suas especificidades, só em conjunto constroem a identidade do documento. (HERMETO, 2012, posição 2406-2412).

A variedade de músicas escolhidas estiveram sempre conectadas com as tematicas que seriam abordadas em sala de aula e a sua função posta como a de documento, como Miriam Hermeto (2012) esclarece em Canção Popular Brasileira e Ensino de História: palavras, sons e tantos sentidos. A escolha desse documento por tema priorizou os pertencentes à tendência de consumo do público infanto juvenil, uma vez que os educandos do This is America se encontram nessa faixa de idade.

Ainda esclarecendo o uso da música em sala, Hermeto salienta que é preciso analisar as variadas dimensões que o documento oferece e buscar o "não isolamento das partes do processo de criação, produção, difusão e apropriação do produto cultural” (HERMETO, 2012, posição 590). Assim, foi criado o esquema abaixo para direcionar aos educandos uma análise qualitativa sobre as músicas usadas em sala que seguisse tais premissas.

Figura 1 - Esquema sobre como analisar

\title{
$\rightarrow$ COMO ANALISAR A MÚSICA
}

\author{
1) Qual o tema central? \\ 2) Qual a linha de argumentação? \\ 3) Qual o recorte temporal na música? \\ 4) Qual o contexto em que foi escrita? \\ 5) Alguma fonte citada (musical e/ou \\ não-musical)? \\ Fonte: Elaborada pelos autores.
}

Outros referenciais teóricos utilizados por Thaís Pacheco e por Júlio César para se entender a adoção da música como documento em sala de aula foi o capítulo "Documentos não escritos em sala de aula: Música e História”, presente no livro Ensino de História: fundamentos e métodos, no qual Circe Bittencourt (2012) salienta as implicações de se utilizar tal material e demonstra formas didáticas e instrutivas de como utilizá-la. Além desse, o capítulo "Canções”, do livro Didática e Prática de Ensino de História, de Selva Guimarães (2003), foi o outro suporte teórico usado em que a autora lista diversas canções brasileiras que podem ser usadas ao abordar variadas temáticas em sala.

\section{Desenvolvimento}

Ao todo foram treze temas ministrados ao longo do primeiro semestre, sendo escolhidos previamente e trabalhados em uma ou mais aulas. Os temas foram: 


\section{A história da música urbana brasileira}

A bolsista Thaís Pacheco delineou a trajetória da música popular urbana desde o século XVIII até a década de 1980/90 e o desenvolvimento de vários gêneros musicais no meio urbano brasileiro, como o samba, a MPB, a bossa nova, o rap e o funk.

\section{Privilégios}

Tratou-se sobre os privilégios socioeconômicos presentes na sociedade brasileira. A dinâmica Caminhada do Privilégio foi escolhida para sensibilizar os alunos sobre as discrepâncias da distribuição de renda no Brasil e as problemáticas sociais presentes no cotidiano de cada um, tanto em relação à sua condição financeira quanto em relação à sua condição social. A dinâmica foi disposta inicialmente com os alunos de pé, lado a lado e, depois de feita cada pergunta relativa aos seus privilégios, eles davam passos para frente ou para trás. Após a dinâmica foi explicado o que é direito e o que é privilégio, demonstrando a diferença entre ambos, e analisou-se a música "Estereótipo", do artista Rashid².

\section{Relacionamentos abusivos}

Foi explicado, primeiramente, o que constitui um relacionamento abusivo e as diferentes manifestações desse tipo de relação. Em segundo lugar a música "Survivor", da banda Destiny’s Child³, foi analisada para demonstrar que, muitas vezes, só se percebe estar na condição de um relacionamento abusivo quando se sai dele, como exposto na letra da música. Após isso, foram elencados 15 indícios de como se dá um relacionamento abusivo e, por fim, o videoclipe da música “Coração Pede Socorro", da artista Naiara Azevedo ${ }^{4}$, feita em parceria com o Governo Federal para conscientizar a população sobre a questão da violência doméstica, foi exposto.

\section{O poder da água}

O documentário “O Poder da Água” (2004) foi exibido. Nele é demonstrado o estudo feito pelo Dr. Masaru Emoto sobre como a energia do local em que a água está propícia ou não a formação de cristais perfeitos nas moléculas de água. Após o documentário, cada aluno produziu um desenho sobre como a música o afeta, de forma positiva ou negativa.

\section{Diferença entre golpe e revolução}

O tema foi trabalhado por meio da reunião dos alunos em grupos pequenos e com a posterior exposição de um podcast que explica e exemplifica a diferença teórica e prática de cada palavra: revolução e golpe. A partir disso Thaís Pacheco pediu para que os alunos, em grupo, montassem esquemas definindo cada uma das palavras. Depois disso a bolsista fez um esquema no quadro para completar possíveis lacunas deixadas pelos alunos em seus respectivos esquemas. Após essa primeira parte, falou-se sobre a resistência que pode

\footnotetext{
2. Composição do artista. Participação vocal de Godô.

3. Composição de Beyoncé Knowles, Anthony Dent e Mathew Knowles.

4. Composição de Waleria Leão, Naiara Azevedo e Rafael Quadros. Vídeo dirigido por Fred Siqueira (Siriguela Filmes).

5. Realizado pelo IHM General Institut.
} 
existir, como existiu ao longo da história, em momentos em que ocorrem golpes ou revoluções. Duas músicas foram tocadas nessa parte da aula, que deram voz a movimentos de resistência em momentos como esses: "Bella Ciao", que simboliza a resistência italiana durante a Segunda Guerra Mundial, e "O Bêbado e a Equilibrista”, interpretada por Elis Regina7 que simboliza a resistência durante a ditadura brasileira.

\section{Educação no Brasil}

Os educandos foram dispostos em grupos e foi pedido para cada um montar um mapa mental ou um esquema que respondesse cinco questões sobre a educação no Brasil: quando se tornou como é hoje; como ocorre; quem está na escola; quanto é investido hoje; e principais desafios atuais. Além disso, foi analisado o EP do Pink Floyd The Wall.

\section{Reflexão sobre o movimento migratório representado no filme Escritores da Liberdade}

Após a exibição completa do filme, foi feita uma roda de conversa para que os educandos pudessem falar sobre as suas percepções acerca do filme e a problemática da migração, que é bem representada na obra. A bolsista Thaís conduziu a roda de conversa, para que pudesse alcançar uma discussão produtiva e interessante sobre o tema.

\section{Migração, Brasil e mundo}

A discussão sobre esse tema foi iniciada após o filme Escritores da Liberdade (2007) ${ }^{8}$ e depois foi aprofundada, tratando sobre os movimentos migratórios, antigos e atuais. Primeiro foi esclarecido o que é migração e como a globalização acabou estimulando esses movimentos ao redor do mundo. Em segundo lugar, a bolsista Thaís explicou os quatro tipos de movimento migratório: 1) Econômico; 2) Cultural e Religioso; 3) Político; e 4) Natural. Em terceiro lugar, os movimentos migratórios brasileiros desde a chegada dos portugueses em 1500, tanto internos quanto externos, foram trabalhados.

\section{Sustentabilidade}

A bolsista Thaís Pacheco desenvolveu um jogo, similar ao jogo de tabuleiro Perfil, no qual os estudantes puderam compreender o que constitui o termo sustentabilidade e as práticas sustentáveis. Para que os discentes pudessem jogá-lo foi feito um tabuleiro humano no chão com bambolês e formados grupos de duas ou três pessoas. Cada carta apresentava um impedidor e um impulsionador do tema central. Além do jogo, foi feito um convite aos educandos para participarem da FEBRAT (Feira Brasileira de Colégios de Aplicação e Escolas Técnicas) por meio da produção e exibição de um podcast relacionado ao tema. Dois grupos de três estudantes aceitaram o convite e ambos foram aceitos para exporem na feira.

6. Interpretada pelo grupo Modena City Ramblers. Composição de autor desconhecido.

7. Composição de João Bosco e Aldir Blanc.

8. Direção e roteiro de Richard LaGravenese. 
Figura 2 - Alunos jogando o jogo Perfil da Sustentabilidade

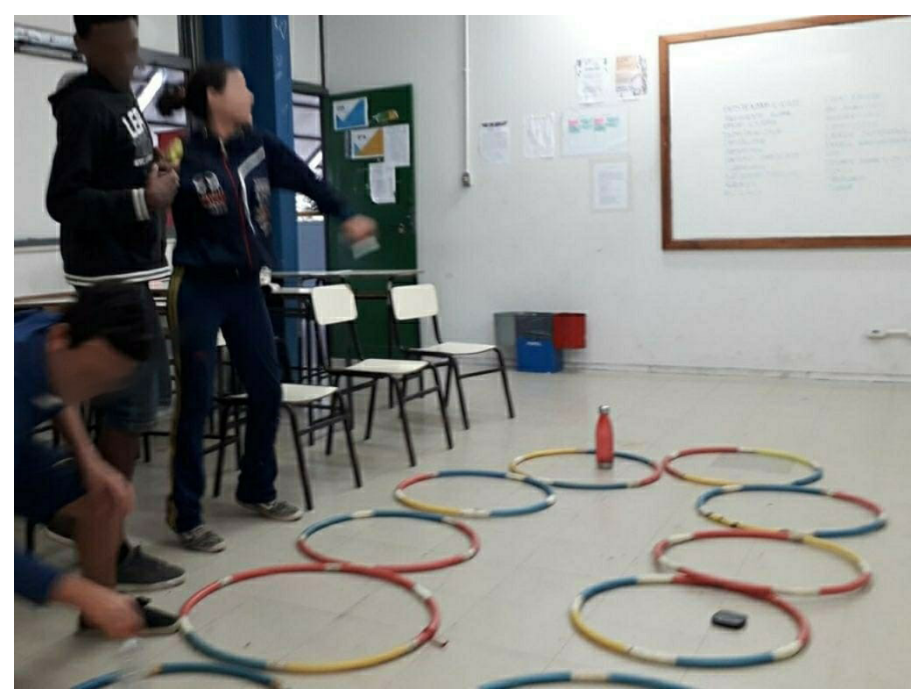

Fonte: Acervo dos autores.

\section{Feminilidade e masculinidade}

Os conceitos do que definem o feminino e o masculino foram trabalhados nesse tema. Para sensibilizar os alunos, primeiro, foi feita uma dinâmica na qual se dava uma caixa para cada aluno de uma vez e pedia para eles falarem o que viam dentro da caixa. Dentro da caixa foi posto um espelho. Ocorreu uma conversa rápida sobre o que eles viram no espelho e foi posto o videoclipe da música "Desconstrução", de Tiago Iorc?. Ambas as provocações, a dinâmica da caixa e a música, foram postas para levantar questões em relação às pressões sofridas pelos educandos por conta da imposição de se ser feminina ou masculino. Além disso, a bolsista Thaís trouxe para a discussão a definição de cada palavra, para que os alunos compreendessem melhor como ocorria cada conjunto de atributos e entendessem como se dá a imposição do ser feminina ou masculino. Por fim, foi pedido para que cada aluno escrevesse em uma folha de papel, de forma anônima, dois tópicos, um sobre o que ainda sentiam necessidade de seguir nos padrões do que é ser feminina ou masculino e um sobre o que tinham deixado de usar desses conjuntos. Cada bilhete foi lido em voz alta para todos os alunos pela bolsista, em busca de mostrar as constantes de cada conjunto de normas. Nessa, o bolsista Marcos Vinícius Liberato e sua turma de GTD se juntaram ao This is America para participar de toda a aula.

\section{Racismo no Brasil}

Tratou-se do que significa racismo e o que constitui uma atitude racista, de acordo com a construção cultural e histórica da sociedade brasileira. Para sensibilizar os alunos, o vídeo A Jornada do $D N A^{10}$ foi exibido, em busca de ilustrar como a miscigenação está presente em todo o mundo e a ausência de motivos para sustentar a ideia de que existe a "raça pura" ou uma "raça superior". Depois foi explicado o que é racismo e as raízes do racismo brasileiro. O relato do ex-árbitro e atual comentarista de futebol, Márcio Chagas da Silva, sobre as suas vivencias como homem negro na sociedade brasileira e, principalmente, no meio futebolístico foi passado para alunos em formato de vídeo"1 . Por fim, a música "Cota não é esmola”,

9. Composição de Tiago lorc. Vídeo dirigido por Tiago lorc, com roteiro de María Elena Morán, Rafael Trindade e Tiago lorc.

10. Elaborado pela empresa Momondo. Disponível em: https://www.youtube.com/watch?v=tyaEQEmt5/s\&ab_channel=momondoLet\%27sOpenOurWorld. Acesso em: 13 jul. 2019.

11. Disponível em: https://www.youtube.com/watch?v=NQNleyWSUVg\&t=183s\&ab_channel=CanalGNT. Acesso em: 13 jul. 2019. 
da artista Bia Ferreira ${ }^{12}$, foi tocada para trazer discussões atuais, como as cotas, que estão ligadas diretamente com o racismo do Brasil. Nessa aula o bolsista Luiz Gustavo Magalhães Alves participou, a convite de Pacheco, para enriquecer a discussão sobre esse tema e para trazer a perspectiva de um indivíduo negro que vive no Brasil.

\section{Análise da música e do videoclipe "This is America"}

A bolsista Thaís, em conjunto com os alunos, realizou uma análise da música de Childish Gambino (2018) e, também, do videoclipe.

\section{Relatos de pessoas que sofreram racismo}

Em busca de reforçar as reflexões abordadas ao longo do semestre em relação à temática do racismo esse tema foi ofertado. Dois vídeos foram postos para os alunos assistirem: "Como o racismo nos deixa doentes", uma TED Talk feita por David R. Williams ${ }^{13}$; e "Eu Empregada Doméstica", uma TED Talk feita por Preta Rara ${ }^{14}$. Após isso, foi estimulada a discussão entre os alunos sobre o que acharam dos vídeos, opiniões a favor ou contra o discurso de cada palestrante, se eles tinham algum relato que gostariam de compartilhar, etc. Por fim, foi dada uma atividade para os alunos fizessem para relacionar essa aula com as outras assistidas ao longo do semestre.

Esses temas foram os escolhidos ao longo do semestre para alcançar os dois objetivos primários estipulados por Júlio César Costa e Thaís Pacheco: sensibilizar e refletir sobre cada temática no cotidiano dos próprios educandos.

\section{Resultados e discussão}

Os resultados apresentados pelo GTD This is America foram variados. É preciso considerar que a matéria foi ofertada para o primeiro semestre de 2019 e teve a duração de quatro meses seguidos, contando com encontros semanais. Essa constância foi bastante benéfica para que práticas, temas e documentos variados fossem utilizados com as três turmas e para mapear o envolvimento de cada turma com a bolsista e a sua participação em cada temática levada para sala de aula.

Como citado acima, foram desenvolvidos ao todo treze temas que geralmente estavam ligados a discussões travadas em meios de interação infanto-juvenis, como nas redes sociais, e utilizados documentos variados para abordar tais temas. Logo, foi perceptível o interesse dos educandos ao estarem diante de aulas com temáticas atuais e que esclarecessem dúvidas sobre questões presentes em seus cotidianos, mas que nem sempre destrinchados e clarificados ao em contato com esses.

A forma de avaliar essa recepção foi por meio de atividades realizadas em sala pelos estudantes, em conjunto ou sozinhos, direcionadas para que esses pudessem expressar as suas noções prévias sobre o tema em questão e, após discussões travadas ao longo da aula, fizessem uma nova versão dessa atividade. Além disso, algumas foram direcionadas para que expressassem seus sentimentos em relação à temática abordada.

Outra forma de avaliar o engajamento das turmas, essa mais contínua, foi a observação das falas, perguntas e respostas feitas pelos estudantes enquanto o documento em análise ou a exposição feita por

12. Composição da artista. Disponível em: https://www.youtube.com/watch?v=QcQlaoHajoM\&ab_channel=SofarLatinAmerica. Acesso em: 13 jul. 2019.

13. Disponível em: https://www.ted.com/talks/david_r_williams_how_racism_makes_us_sick?language=pt. Acesso em: 13 jul. 2019.

14. Disponível em: https://www.youtube.com/watch?v=_d_n-z3s8Lo\&vl=pt-BR. Acesso em: 13 jul. 2019. 
Thaís Pacheco eram projetados. Essa forma avaliativa é menos palpável que a citada no parágrafo anterior, entretanto foi importante para ponderar o prosseguimento ou não do percurso delineado por Costa e Pacheco previamente de acordo com o envolvimento dos educandos.

Por fim, vale ressaltar a participação de seis estudantes, divididos em dois grupos de três integrantes, do This is America na FEBRAT. A participação se deu por meio do desenvolvimento de podcasts relacionados ao tema da feira Bioeconomia: Diversidade e Riqueza para o Desenvolvimento Sustentável. Um grupo fez três episódios sobre a sustentabilidade na moda têxtil ${ }^{15} \mathrm{e}$ o outro fez um episódio único sobre o plástico no meio ambiente ${ }^{16}$. Ambos os projetos fizeram com que os envolvidos estudassem bastante sobre o tema, aprendessem exercícios vocais e entendessem todo o processo criativo que envolve a produção de um podcast, uma forma de entretenimento que tem cada vez mais sido consumida.

\section{Figura 3 - Grupo gravando o podcast sobre sustentabilidade na moda têxtil}

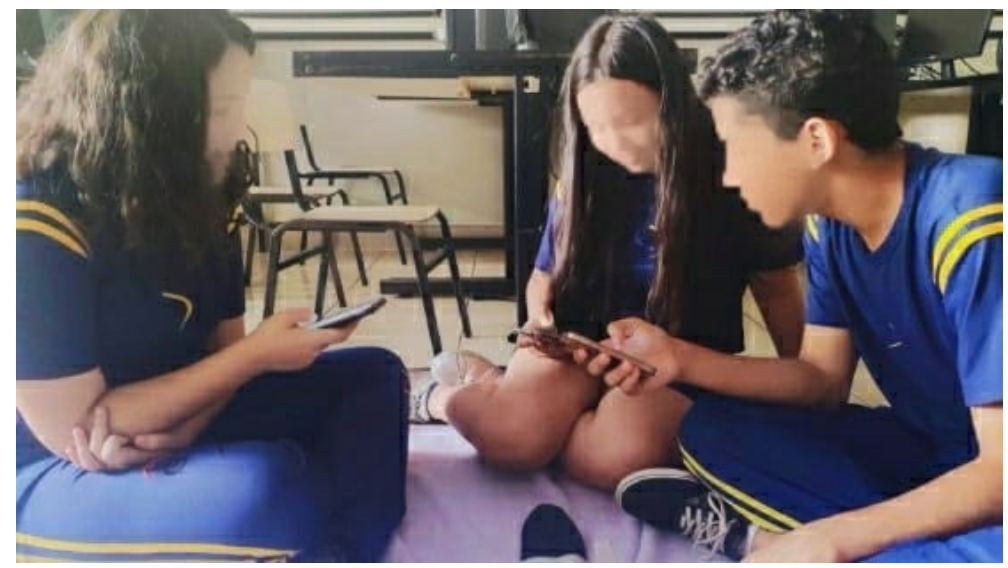

Fonte: Acervo dos autores.

\section{Considerações finais}

Neste contexto atual verificamos que o Centro Pedagógico da UFMG busca, com a implementação dos Grupos de Trabalho Diferenciados, uma reforma curricular que atenda sobremaneira questões muitas vezes postas pelos educandos em relação à escola. Como por exemplo, no sempre dito, de que a escola ou as disciplinas não estão conectadas com a realidade dos educandos.

Diante da multiplicidade de temas e do formato adotado pelo This is America, no qual sempre houve espaço para o diálogo, para a troca de experiências e reflexões, constatamos que os objetivos foram alcançados. Outra fonte de observação para os apontamentos feitos pelo dado artigo foi o perceptível interesse dos educandos ao estarem diante de aulas com temáticas atuais e formatos diferenciados, apresentando grande mobilização por parte dos próprios.

A participação dos grupos de estudantes na FEBRAT é outro indicador de como esse GTD foi mobilizador de ações e como possibilitou uma socialização mais ampla no meio acadêmico, a nível nacional e internacional, pois, recebemos no evento estudantes de países da América Latina.

Verificamos também que os Grupos de Trabalho Diferenciado, de maneira geral, buscam e buscarão para a comunidade do Centro Pedagógico o desenvolvimento da autonomia dos educandos, pois, cada um escolhe quais irá participar, por meio da observação dos resumos, sendo aluno de três a cada semestre.

15. Esses episódios encontram-se na plataforma SoundCloud. Para acessá-la use o link https://soundcloud.com/thaisrpacheco/ sets/this-is-america-7-febrat.

16. Esse episódio encontra-se na plataforma SoundCloud. Para acessá-la use o link https://soundcloud.com/thaisrpacheco/sets/ this-is-america-sustentabilidade-7febrat. 
Por fim, foi possível identificar os benefícios que esse trabalho traz à comunidade educativa do Centro Pedagógico da UFMG, uma vez que abordar as questões da atualidade na vida dos jovens é capaz de mobilizar muitas reflexões e relatos de como esses têm interesse em conhecer e debater essas questões. Essa iniciativa pode ser muito pertinente para gerar uma pesquisa que envolva outros estudantes desta comunidade sobre como percebem o GTD e suas contribuições ao CP/UFMG e à academia.

\section{Referências}

BITTENCOURT, Circe Maria Fernandes. Documentos não escritos em sala de aula: música e história. In: BITTENCOURT, Circe Maria Fernandes. Ensino de História: fundamentos e métodos. 2. ed. São Paulo: Cortez, 2012. p. 378-400.

CHILDISH Gambino - This is America. [S. l.: s. n.], 2018. 1 vídeo (4 min 04 s). Publicado pelo canal Donald Glover. Disponível em: https://www.youtube.com/watch?v=VYOjWnS4cMY. Acesso em: 10 out. 2019.

GUIMARÃES, Selva. Canções. In: GUIMARÃES, Selva. Didática e Prática de Ensino de História. 13. ed. Campinas: Papirus, 2003. p. 285-313.

HERMETO, Miriam. Canção Popular Brasileira e o Ensino de História: palavras, sons e tantos sentidos. Belo Horizonte: Autêntica, 2012. E-book.

Data de submissão: 05/06/2020

Data de aceite: $22 / 06 / 2020$ 